\title{
Human Problem Solving in 2010
}

\author{
Zygmunt Pizlo
}

\begin{abstract}
This paper presents a bibliography of 100 references related to human problem solving, arranged by subject matter. The references were taken from PsycInfo database. Journal papers, book chapters, and dissertations are included. The topics include human development, education, neuroscience, and research in applied settings, as well as animal studies.
\end{abstract}

\section{Introduction}

Similarly to what I found in my reviews two and four years ago, the ratio of the number of journal papers (78) to the number of journals where the papers appeared (56) is barely greater than one. Both of these numbers are smaller by a factor of two compared to 2008 and similar to (but slightly smaller than) the corresponding numbers in 2006. The number of dissertations (11) is substantially smaller than the corresponding numbers in 2006 and 2008 (23 and 70, respectively).

There is no indication that volume of research on human problem solving is increasing.The number of published reports is substantially smaller than in other areas of cognition, such as perception or learning and memory. It seems that the lack of reliable experimental methodology, as well as the absence of theoretical foundations are responsible for this state of affairs. No doubt, studying problem solving is difficult. The underlying mental phenomena are complex and difficult to measure objectively. It seems to me that the current situation of our field can be changed by the use of computational models as ways of (i) explaining the mental mechanisms involved in problem solving and (ii) guiding empirical research. It is obvious to everyone that solving math or physics problems is a part of problem solving. Just look at Polya's books, starting with his wonderful "How to solve it?" (1945). So, the main problem with"problem solving" may not be related to the absence of a definition of the field. If someone were able to formulate a computational model that can solve math and physics problems the way good students do, we would have a real breakthrough in the study of problem solving. So, why not work on it? Similarly with games such as chess. There is already a very good

Purdue University, Department of Psychological Sciences, 703 Third Street, West Lafayette, IN 47907-2081 Email:pizlo@pysclops.psych.purdue.edu 
chess playing algorithm, except that this algorithm has little to do with mental mechanisms. So, why not modify it and make it more similar to human chess players? Formulating decent computational models for solving math and physics problems or playing difficult games would be of great interest to cognitive psychologists. With such models at hand, it should be much easier to design interesting and informative experiments that would compare human and model performance. In fact, this is how research on visual perception, arguably the most mature and successful part of cognitive psychology, has been progressing during the last couple of decades. This conjecture points into the direction of interdisciplinary, collaborative research of cognitive psychologists and computer scientists interested in problem solving. The recent Dagstuhl Seminar on problem solving was a step in this direction.(See http://www.dagstuhl.de/ en/program/calendar/semhp/?semnr=11351.) This approach is not entirely new-it was tried but failed half a century ago. The main reason for optimism at this point is the fact that both computer science and cognitive psychology are well developed sciences. In addition, existing computers can handle enormous problem spaces that could not have been tried in the 1950s. But being able to handle large problem spaces will not be sufficient. Intelligent, human-like problem solving will surely require forming adequate representations of a problem. The nature of problem representation was, in fact, the main topic motivating the Dagstuhl Seminar. Recall that the role of problem representation was emphasized by the Gestalt Psychologists almost 100 years ago. It seems that the Gestaltists were ahead of their time. Again, using the analogy with the field of visual perception, Gestaltists' theories of vision, presented in the 1920s and 1930s, could not "materialize" without the Information Theory (formulated in 1948), without computers (built in 1941) and without a formal theory of Inverse Problems (developed in the 1960s). Can "representational complexity", a concept analogous to "computational complexity" be the missing theoretical tool that will prove critical in implementing the Gestalt ideas about problem solving? The first answers to this question may come at the next Dagstuhl Seminar that is being planned, as you read this introduction.

\section{List of Journals}

(The number of publications per each journal, if greater than one, is shown in parentheses) ACM Transactions On Computer-Human Interaction

Al Communications

Animal Behaviour

Animal Cognition

Annual Review Of Neuroscience

Applied Cognitive Psychology

Artificial Intelligence In Medicine

Artificial Intelligence Review

Behavioral And Brain Functions

British Journal Of Psychology 
Cognition

Cognitive Processing

Cognitive Science

Cognitive Systems Research

Computers \& Education (3)

Computers In Human Behavior (6)

Current Anthropology

Decision Sciences Journal Of Innovative Education

Educational Psychology Review (3)

Experimental Aging Research

Hippocampus

Human Brain Mapping

Human Factors

Human Physiology

Human Resource Development Review

Instructional Science

International Journal Of Human-Computer Interaction

International Journal Of Human-Computer Studies (2)

Japanese Journal Of Educational Psychology

Journal Of Experimental Child Psychology

Journal Of Experimental Psychology: General

Journal Of Experimental Psychology: Learning, Memory, And Cognition (3)

Journal of Experimental Social Psychology

Journal Of Machine Learning Research

Journal Of Mathematical Psychology

Journal of Problem Solving (4)

Journal of the Operational Research Society

Knowledge-Based Systems

Learning And Instruction

Memory \& Cognition

Mind, Brain, And Education

Minds And Machines

Neurocomputing: An International Journal

Psychologia: An International Journal Of Psychological Sciences

Psychological Bulletin (2)

Psychological Methods

Psychological Review (2)

Psychological Reports 


\author{
Psychological Science \\ Quarterly Journal Of Experimental Psychology (6) \\ Review Of General Psychology \\ Review of Marketing Science \\ Social Networks \\ Spatial Cognition And Computation \\ Studia Psychologica \\ Theoretical Issues In Ergonomics Sciencei
}

\title{
Bibliography
}

\section{General}

Andrews, R. L., Brusco, M. J., Currim, I. S., \& Davis, B. (2010). An empirical comparison of methods for clustering problems: Are there benefits from having a statistical model? Review of Marketing Science, 8(1), article 3, pages 1-32.

Baars, B. J. (2010). Spontaneous repetitive thoughts can be adaptive: Postscript on "mind wandering". Psychological Bulletin, 136(2), 208-210.

Badets, A., Pesenti, M., \& Olivier, E. (2010). Response-effect compatibility of finger-numeral configurations in arithmetical context. The Quarterly Journal of Experimental Psychology, 63(1), 16-22.

Beaman,P.C.(2010).Working memory and working attention.Current Anthropology, 51(s1), S27-S38.

Bhattacharyya, S., \& Ohlsson, S. (2010). Social creativity as a function of agent cognition and network properties: A computer model. Social Networks, 32(4), 263-278.

Campitelli, G., \& Gobet, F.(2010). Herbert Simon's decision-making approach:Investigation of cognitive processes in experts. Review of General Psychology, 14(4), 354-364.

Chein, J., Weisberg, R., Streeter, N., \& Kwok, S. (2010). Working memory and insight in the nine-dot problem. Memory \& Cognition, 38(7), 883-892.

Chu, Y., Li, Z., Su, Y. \& Pizlo, Z. (2010) Heuristics in Problem Solving:The Role of Direction in Controlling Search Space. Journal of Problem Solving, 3, 27-51.

Das, R., LeFevre, J., \& Penner-Wilger, M. (2010). Negative numbers in simple arithmetic. The Quarterly Journal of Experimental Psychology, 63(10), 1943-1952.

DeCaro, M.S., \& Beilock, S.L.(2010).The benefits and perils of attentional control.In B. Bruya, B. (Ed.), Effortless attention: A new perspective in the cognitive science of attention and action (pp. 51-73). Cambridge, MA US: MIT Press.

Gilhooly, K. J., Fioratou, E. E., \& Henretty, N. N. (2010). Verbalization and problem solving: Insight and spatial factors. British Journal of Psychology, 101(1), 81-93.

Hélie, S., \& Sun, R. (2010).Incubation, insight, and creative problem solving: A unified theory 
and a connectionist model. Psychological Review, 117(3), 994-1024.

Howe, M.L., Garner, S.R., Dewhurst, S.A.\& Ball,L.J.(2010) Can false memories prime problem solutions? Cognition, 117, 176-181.

Hurley, S. M., \& Novick, L. R. (2010). Solving problems using matrix, network, and hierarchy diagrams: The consequences of violating construction conventions. The Quarterly Journal of Experimental Psychology, 63(2), 275-290.

Knauff, M., \& Wolf, A.G. (2010). Complex cognition:The science of human reasoning, problem-solving, and decision-making. Cognitive Processing, 11(2), 99-102.

Köhn, H.-F., Steinley, D., \& Brusco, M. J. (2010). The p-median model as a tool for clustering psychological data. Psychological Methods, 15(1), 87-95.

Kong,X.,Schunn,C.D., \&Wallstrom, G.L.(2010). High regularities in eye movement patterns reveal the dynamics of the visual working memory allocation mechanism. Cognitive Science: A Multidisciplinary Journal, 34(2), 322-337.

Mitchum, A. L., \& Kelley, C. M. (2010). Solve the problem first: Constructive solution strategies can influence the accuracy of retrospective confidence judgments. Journal of Experimental Psychology: Learning, Memory, and Cognition, 36(3), 699-710.

Moss, J., Kotovsky, K., \& Cagan, J. (2010). The effect of incidental hints when problems are suspended before, during, or after an impasse. Journal of Experimental Psychology: Learning, Memory, and Cognition, 37(1), 140-148

Orrantia, J., Rodríguez, L., \& Vicente, S. (2010). Automatic activation of addition facts in arithmetic word problems. The Quarterly Journal of Experimental Psychology, 63(2), 310-319.

Osman, M.(2010).Controlling uncertainty: A review of human behavior in complex dynamic environments. Psychological Bulletin, 136(1), 65-86.

Patsenko,E.G., \& Altmann,E.M.(2010).How planful is routine behavior? A selective-attention model of performance in the Tower of Hanoi. Journal of Experimental Psychology: General, 139(1), 95-116.

Renkl, A., \& Atkinson, R.K. (2010). Learning from worked-out examples and problem solving. In J. L. Plass, R. Moreno, R. Brünken, J. L. (Eds.), Cognitive load theory (pp. 91-108). New York, NY US: Cambridge University Press.

Ruisel, I. (2010). Human knowledge in the context of cognitive psychology. Studia Psychologica, 52(4), 267-284.

Sanborn, A. N., Griffiths, T. L., \& Navarro, D. J. (2010). Rational approximations to rational models: Alternative algorithms for category learning. Psychological Review, 117(4), 1144-1167.

Schroyens,W.(2010). Mistaking the instance for the rule:A critical analysis of the truth-table evaluation paradigm. The Quarterly Journal of Experimental Psychology, 63(2), 246-259.

Slepian, M.L., Weisbuch, M., Rutchick, A.M., Newman, L.S. \& Ambady, N. (2010) Shedding light on insight:Priming bright ideas.Journal of Experimental Social Psychology.46(4), 
696-700.

Son, J.Y., Doumas, L.A.A. \& Goldstone, R.L. (2010) When Do Words Promote Analogical Transfer? Journal of Problem Solving, 3, 52-92.

Storm, B.C.\& Angello,G.(2010). Overcoming fixation:Creative problem solving and retrievalinduced forgetting. Psychological Science, 21, 1263-1265.

Thevenot, C., Castel, C., Fanget, M., \& Fayol, M. (2010). Mental subtraction in high- and lower skilled arithmetic problem solvers: Verbal report versus operand-recognition paradigms.Journal of Experimental Psychology: Learning, Memory, and Cognition, 36(5), $1242-1255$.

Thompson,V.A.(2010).Towards a metacognitive dual process theory of conditional reasoning. In M.Oaksford, N.Chater.(Eds.), Cognition and conditionals: Probability and logic in human thinking (pp. 335-354). New York, NY US: Oxford University Press.

Touroutoglou, A., \& Efklides, A. (2010).Cognitive interruption as an object of metacognitive monitoring: Feeling of difficulty and surprise. In A. Efklides, P. Misailidi. (Eds.), Trends and prospects in metacognition research (pp. 171-208). New York, NY US: Springer Science + Business Media.

Walwyn, A.L. \& Navarro, D.J. (2010) Minimal Paths in the City Block: Human Performance on Euclidean and Non-Euclidean Traveling Salesperson Problems. Journal of Problem Solving, 3, 93-105.

Wang,Y., \& Chiew, V. (2010). On the cognitive process of human problem solving. Cognitive Systems Research, 11(1), 81-92.

Zhang, S., \& Lee, M.D. (2010). Optimal experimental design for a class of bandit problems. Journal of Mathematical Psychology, 54(6), 499-508.

\section{Developmental}

Agostino, A., Johnson, J., \& Pascual-Leone, J. (2010). Executive functions underlying multiplicative reasoning: Problem type matters. Journal of Experimental Child Psychology, 105(4), 286-305.

Blachman,D.R., \& Esposito, L.(2010).Getting started:Answering your frequently asked questions about applied research on child and adolescent development. In V. Maholmes, C. Lomonaco (Eds.), Applied research in child and adolescent development: A practical guide (pp. 7-35). New York, NY US: Psychology Press.

Margrett, J.A., Allaire, J.C., Johnson,T.L., Daugherty, K.E., \&Weatherbee, S. R. (2010). Everyday problem solving. In J. C. Cavanaugh, C. K. Cavanaugh, J. Berry, R. West, (Eds.) , Aging in America, Vol 1: Psychological aspects (pp.80-101).Santa Barbara, CA:Praeger/ABC-CLIO.

Miller, L., \& West, R. L. (2010). The effects of age, control beliefs, and feedback on selfregulation of reading and problem solving. Experimental Aging Research, 36(1), 40-63.

Soltész, F., Sz CS, D., \& Sz CS, L. (2010). Relationships between magnitude representation, counting and memory in 4- to 7-year-old children: A developmental study. Behavioral and Brain Functions, 6.

- volume 4, no. 1 (Winter 2012) 


\section{Education}

Boekaerts, M., \& Rozendaal, J. S. (2010). Using multiple calibration indices in order to capture the complex picture of what affects students' accuracy of feeling of confidence. Learning and Instruction, 20(5), 372-382.

Cuenca López, J. M., \& Martín Cáceres, M. J. (2010).Virtual games in social science education. Computers \& Education, 55(3), 1336-1345.

Kalyuga, S., Renkl, A., \& Paas, F.(2010). Facilitating flexible problem solving:A cognitive load perspective. Educational Psychology Review, 22(2), 175-186.

Loewenstein, J. (2010). How one's hook is baited matters for catching an analogy. In B. H. Ross (Ed.), The psychology of learning and motivation: Advances in research and theory (Vol 53) (pp. 149-182). San Diego, CA US: Elsevier Academic Press.

Manches, A., O'Malley, C., \& Benford, S. (2010). The role of physical representations in solving number problems: A comparison of young children's use of physical and virtual materials. Computers \& Education, 54(3), 622-640.

Paek,P.L.(2010).Factors contributing to gender differences in mathematics performance of United States high school students. In H.J.Forgasz, J.Becker, K. Lee, O. Steinthorsdottir (Eds.) , International perspectives on gender and mathematics education (pp. 203-224). Greenwich, CT US: IAP Information Age Publishing.

Salden, R. M., Aleven, V., Schwonke, R., \& Renkl, A. (2010). The expertise reversal effect and worked examples in tutored problem solving. Instructional Science, 38(3), 289-307.

Salden, R. M., Koedinger, K. R., Renkl, A., Aleven, V., \& McLaren, B. M. (2010). Accounting for beneficial effects of worked examples in tutored problem solving. Educational Psychology Review, 22(4), 379-392.

Seal, K., Przasnyski, Z. H., \& Leon, L. A. (2010). How levels of interactivity in tutorials affect students' learning of modeling transportation problems in a spreadsheet. Decision Sciences Journal of Innovative Education, 8(1), 75-94.

Seo, Y., \& Woo, H. (2010). The identification, implementation, and evaluation of critical user interface design features of computer-assisted instruction programs in mathematics for students with learning disabilities. Computers \& Education, 55(1), 363-377.

Singer, F., \& Voica, C. (2010). In search of structures: How does the mind explore infinity? Mind, Brain, and Education, 4(2), 81-93.

Stieff, M., \& Raje, S. (2010). Expert algorithmic and imagistic problem solving strategies in advanced chemistry. Spatial Cognition and Computation, 10(1), 53-81.

Swalander, L., \& Folkesson, A. (2010). Computer use in a primary school: A case-study of self-regulated learning. In A. Efklides, P. Misailidi. (Eds.), Trends and prospects in metacognition research (pp.395-425). New York, NY US:Springer Science + Business Media.

Tachibana, H., \& Fujimura, N.(2010). Knowledge integration through collaborative problemsolving in high school students: Others as partners in co-constructing knowledge. Japanese Journal of Educational Psychology, 58(1), 1-11.

Wittwer, J., \& Renkl, A. (2010). How effective are instructional explanations in example- 
based learning? A meta-analytic review.Educational Psychology Review, 22(4),393-409.

\section{Applied}

Baker, R.D., D'Mello, S. K., Rodrigo, M.T., \& Graesser, A.C. (2010). Better to be frustrated than bored:The incidence, persistence, and impact of learners' cognitive-affective states during interactions with three different computer-based learning environments. International Journal of Human-Computer Studies, 68(4), 223-241.

DeCaro, M. S., Rotar, K. E., Kendra, M. S., \& Beilock, S. L. (2010). Diagnosing and alleviating the impact of performance pressure on mathematical problem solving. The Quarterly Journal of Experimental Psychology, 63(8), 1619-1630.

Fern, X., Komireddy, C., Grigoreanu, V., \& Burnett, M. (2010). Mining problem-solving strategies from HCl data. ACM Transactions on Computer-Human Interaction, 17(1), 1-22.

Fiore, S. M., Rosen, M. A., Smith-Jentsch, K. A., Salas, E., Letsky, M., \& Warner, N. (2010).Toward an understanding of macrocognition in teams: Predicting processes in complex collaborative contexts. Human Factors, 52(2), 203-224.

Fiore, S. M., Smith-Jentsch, K. A., Salas, E., Warner, N., \& Letsky, M. (2010). Towards an understanding of macrocognition in teams: Developing and defining complex collaborative processes and products. Theoretical Issues in Ergonomics Science, 11(4), 250-271.

Gómez-Pérez, J., Erdmann, M., Greaves, M., Corcho, O., \& Benjamins, R. (2010). A framework and computer system for knowledge-level acquisition, representation, and reasoning with process knowledge. International Journal of Human-Computer Studies, 68(10), 641-668.

Groen, M., \& Noyes, J. (2010). Solving problems: How can guidance concerning task-relevancy be provided? Computers in Human Behavior, 26(6), 1318-1326.

Hansen, M., \& Spada, H. (2010). Supporting remote collaborative problem-solving. Applied Cognitive Psychology, 24(9), 1297-1323.

Jeong, H., \& Hmelo-Silver, C. E. (2010). Productive use of learning resources in an online problem-based learning environment. Computers in Human Behavior, 26(1), 84-99.

Lohman, M.C. (2010). An unexamined triumvirate:Dogmatism, problem solving, and HRD. Human Resource Development Review, 9(1), 72-88.

Ludwig, S. A. (2010).Comparison of a deductive database with a semantic web reasoning engine. Knowledge-Based Systems, 23(6), 634-642.

Mayotte, S. (2010). Online assessment of problem solving skills. Computers in Human Behavior, 26(6), 1253-1258.

Ntuen, C. A., Park, E. H., \& Gwang-Myung, K. (2010). Designing an information visualization tool for sensemaking. International Journal of Human-Computer Interaction, 26(2-3), 189-205.

Robinson, A.E., Sloman, S.A., Hagmayer, Y. \& Hertzog, C.K. (2010) Causality in Solving Economic Problems. Journal of Problem Solving, 3, 106-130. 
Scheel, M.H. (2010). Resource depletion promotes automatic processing: Implications for distribution of practice. Psychological Reports, 107(3), 860-872.

Schreiber, M., \& Engelmann,T.(2010).Knowledge and information awareness for initiating transactive memory system processes of computer-supported collaborating ad hoc groups. Computers in Human Behavior, 26(6), 1701-1709.

Spada, H. (2010). Of scripts, roles, positions, and models. Computers in Human Behavior, 26(4), 547-550.

Tanaka, K., \& Yamaoka, T. (2010). Understanding characteristics of the transfer of mental models in the use of electrical devices. Psychologia: An International Journal of Psychological Sciences, 53(4), 256-266.

Walraven, A., Brand-Gruwel,S., \& Boshuizen, H.A.(2010). Fostering transfer of websearchers' evaluation skills: A field test of two transfer theories. Computers in Human Behavior.

\section{Neuroscience}

Cisek, P., \& Kalaska, J.F.(2010). Neural mechanisms for interacting with a world full of action choices. Annual Review of Neuroscience, 33, 269-298.

Koshelkov, D. A., \& Machinskaya, R. I. (2010). Functional coupling of cortical areas during problem-solving task:Analysis of rhythm coherence.Human Physiology, 36(6),665-669.

Moses, S. N., Brown, T. M., Ryan, J. D., \& Mcintosh, A. (2010). Neural system interactions underlying human transitive inference. Hippocampus, 20(8), 894-901.

Newman, S.D., Pruce, B., Rusia, A. \& Burns Jr., T. (2010) The Effect of Strategy on Problem Solving: An fMRI Study. Journal of Problem Solving, 3, 1-26.

Revet-ben, C., Cherubini, P.,Frackowiak, R.J.,Caltagirone,C.,Paulesu, E., \& Macaluso, E.(2010). Conditional and syllogistic deductive tasks dissociate functionally during premise integration. Human Brain Mapping, 31(9), 1430-1445.

\section{Animal}

Smith, B., \& Litchfield, C. (2010). How well do dingoes, Canis dingo, perform on the detour task? Animal Behaviour, 80(1), 155-162.

Vlamings, P. M., Hare, B., \& Call, J. (2010). Reaching around barriers: The performance of the great apes and 3-5-year-old children. Animal Cognition, 13(2), 273-285.

\section{Artificial Intelligence}

Condell, J., Wade, J., Galway, L., McBride, M., Gormley, P., Brennan, J., \& Somasundram, T. (2010). Problem solving techniques in cognitive science. Artificial Intelligence Review, $34(3), 221-234$.

Doctor, J. N., \& Strylewicz, G. (2010). Detecting 'wrong blood in tube' errors: Evaluation of a Bayesian network approach. Artificial Intelligence in Medicine, 50(2), 75-82. doi:10.1016/j.artmed.2010.05.008 
Eglese RW and Black D. (2010) Optimizing the routing of vehicles', in Green Logistics: Improving the Environmental Sustainability of Logistics, (eds) McKinnon A, Cullinane S, Whiteing A and Browne M, Kogan Page, London, 215-228.

Kojima, K., Perrier, E., Imoto, S., \& Miyano, S. (2010). Optimal search on clustered structural constraint for learning Bayesian network structure. Journal of Machine Learning Research, 11.

Maden,W., Eglese, R.W.\& Black, D. (2010) Vehicle routing and scheduling with time-varying data: A case study. Journal of the Operational Research Society, 61(3), 515-522.

Pulina, L. (2010). Engineering portfolios of machine learning algorithms to solve complex tasks in robotics and automated reasoning. Al Communications, 23(1), 61-63.

Taylor, J. G. (2010). On artificial brains. Neurocomputing: An International Journal.

Zamani, R.(2010). An object-oriented view on problem representation as a search-efficiency facet: Minds vs. Machines. Minds and Machines, 20(1), 103-117.

\section{Dissertations}

Afolabi, M. (2010).Creative decision within a group through a systems-based process. Dissertation Abstracts International, 71.

Alfano, K. M. (2010). A human factors approach to file storage and retrieval. Dissertation Abstracts International, 70.

Anastasiade,J.V.(2010). Instructional strategies for developing problem-solving skills:The worked-example effect using ill-structured visual pattern recognition problems. Dissertation Abstracts International Section A, 70.

Dandurand, F. (2010). Computational modeling of learning in complex problem solving tasks. Dissertation Abstracts International, 70.

King, L. A. (2010).The influence of individual differences on diagrammatic communication and problem representation. Dissertation Abstracts International Section A, 71.

Kong,X. (2010). Roles of visual working memory, global perception and eye-movement in visual complex problem solving. Dissertation Abstracts International, 70.

Larson, M. E. (2010). Transfer of learning: The effects of different instruction methods on software application learning. Dissertation Abstracts International, 71.

Liang, H. (2010). Interaction design and visual cognitive tools: Enabling effective humaninformation interaction. Dissertation Abstracts International, 70.

Reese, J. (2010). Examining intuitive-creativity via reading Tarot cards in a person-centered climate. Dissertation Abstracts International, 71.

Schauer, G. (2010). Attentional scope and performance in solving relational figure matrix puzzles. Dissertation Abstracts International, 71.

Toldy, M. E. (2010). The impact of working memory limitations and distributed cognition on solving search problems on complex informational websites. Dissertation Abstracts International, 70. 